\title{
Correction to: Emerging technologies for the pretreatment of lignocellulosic materials for bio-based products
}

\author{
Nasir Ali ${ }^{1,2} \cdot$ Quan Zhang ${ }^{1} \cdot$ Zi-Yong Liu $^{2} \cdot \mathrm{Fu}^{\mathrm{Li} \mathrm{Li}} \mathrm{Li}^{2} \cdot \mathrm{Ming} \mathrm{Lu}^{2,3} \cdot$ Xiang-Chen Fang $^{1}$
}

Published online: 27 April 2020

(C) Springer-Verlag GmbH Germany, part of Springer Nature 2020

\section{Correction to: Applied Microbiology and Biotechnology (2020) 104:455-473} https://doi.org/10.1007/s00253-019-10158-w

This corrects the article "Emerging technologies for the pretreatment of lignocellulosic materials for bio-based products" in volume 104, with page no 455-473, (https://doi.org/10. 1007/s00253-019-10158-w).

Two affiliation's orders were published incorrectly. The authors apologize for any inconvenience that it may have caused.

The correct affiliations are: Nasir $\mathrm{Ali}^{1,2}$, Quan Zhang ${ }^{1}$, Zi-Yong $\mathrm{Liu}^{2}, \mathrm{Fu}-\mathrm{Li} \mathrm{Li}^{2}$, Ming $\mathrm{Lu}^{2,3}$, and Xiang-Chen Fang ${ }^{1 *}$

The online version of the original article can be found at https://doi.org/ 10.1007/s00253-019-10158-w

Ming Lu

lvming@qibebt.ac.cn

$\triangle$ Xiang-Chen Fang

fangxiangchen.fshy@sinopec.com

1 Sinopec Dalian (Fushun) Research Institute of Petroleum and Petrochemicals, Dalian, China

2 Key Laboratory of Biofuels, Qingdao Institute of Bioenergy and Bioprocess Technology, Chinese Academy of Sciences, Qingdao 266101, China

3 Dalian National Laboratory for Clean Energy, Dalian 116023, China 